\title{
Drug treatment patterns in bipolar disorder: analysis of long-term self-reported data
}

\author{
Michael Bauer ${ }^{1 *}$, Tasha Glenn², Martin Alda ${ }^{3}$, Kemal Sagduyu4, Wendy Marsh ${ }^{5}$, Paul Grof ${ }^{6,7}$, Rodrigo Munoz ${ }^{8}$, \\ Emanuel Severus ${ }^{1}$, Philipp Ritter ${ }^{1}$ and Peter C Whybrow ${ }^{9}$
}

\begin{abstract}
Background: The objective of this study is to investigate drug treatment patterns in bipolar disorder using daily data from patients who received treatment as usual.

Methods: Patients self-reported the drugs taken daily for about 6 months. Daily drug use and drug combinations were determined for each patient, both by the specific drugs and by medication class. The drug load was calculated for all drugs taken within a medication class.

Results and discussion: Four hundred fifty patients returned a total of 99,895 days of data (mean 222.0 days). The most frequently taken drugs were mood stabilizers. Of the 450 patients, 353 (78.4\%) took a stable drug combination for $\geq 50 \%$ of days. The majority of patients were taking polypharmacy, including $75 \%$ of those with a stable combination. Only a small number of drugs were commonly taken within each medication class, but there were a large number of unique drug combinations: 52 by medication class and 231 by specific drugs. Eighty percent of patients with a stable combination were taking three or less drugs daily. Patients without a stable combination took drugs but made frequent changes. Taking more than one drug within a medication class greatly increased the drug load.

To summarize, (1) patients were more likely to take a mood stabilizer than any other drug; (2) although most patients were taking polypharmacy, there were no predominant drug regimens even among those taking a stable combination; and (3) most patients with a stable combination take a relatively small number of drugs daily. The wide variation in drug regimens and numerous possible drug combinations suggest that more evidence is needed to optimize treatment of bipolar disorder.
\end{abstract}

Keywords: Bipolar disorder, Drug treatment patterns, Drug load, Polypharmacy

\section{Background}

Drug treatment of bipolar disorder is a difficult challenge due to the recurrent, episodic, and heterogeneous nature of the disease. In recent studies, less than one third of patients in the USA and about half of those in Europe received monotherapy, while the balance received polypharmacy (Azorin et al. 2009; Baldessarini et al. 2008a, b; Goldberg et al. 2009; Hayes et al. 2011; Quante et al. 2010). Many factors have contributed to the increasing use of polypharmacy for bipolar disorder. A substantial proportion of patients do not respond

\footnotetext{
*Correspondence: Michael.Bauer@uniklinikum-dresden.de

'Department of Psychiatry and Psychotherapy, Universitätsklinikum Carl Gustav Carus, Technische Universität Dresden, Fetscherstr. 74, Dresden 01307, Germany

Full list of author information is available at the end of the article
}

adequately to monotherapy, and additional drugs are required to achieve acute stability and reduce relapses (Goldberg et al. 2009; Frye et al. 2000; Lin et al. 2006; Malhi et al. 2012; Post et al. 2010). There is increased recognition that even while euthymic, patients experience frequent subsyndromal symptoms (Bauer et al. 2010) and an impaired quality of life (Michalak et al. 2005). The drugs available for long-term maintenance have different efficacy for preventing mania and depression, suggesting the need for complimentary agents (Smith et al. 2007). Additionally, with the expansion of drugs available for bipolar disorder such as newgeneration antipsychotics and antidepressants, and with psychiatric indications for anticonvulsants, there are numerous choices for the prescriber. Prior research on drug treatment patterns is primarily based on health

\section{实}


plan claims (Baldessarini et al. 2007, 2008a) or physician prescribing records (Azorin et al. 2009; Goldberg et al. 2009; Hayes et al. 2011; Quante et al. 2010). This study explored drug treatment patterns in bipolar disorder using 6 months of daily self-reported data on psychotropic drug intake.

\section{Methods}

Data were obtained from an ongoing, long-term naturalistic study in which patients with bipolar disorder recorded mood, sleep, and drugs taken daily (Bauer et al. 2012). All study participants have a diagnosis of bipolar disorder by DSM-IV criteria, are at least 18 years old, receive pharmacological treatment, and agreed to use selfreporting software daily for 6 months. The study has minimal inclusion criteria to better represent the patient heterogeneity of clinical practice. The diagnosis of bipolar disorder was made by the prescribing psychiatrist in a clinical interview. The demographic profile of the patients in this study is similar to those who participated in five large studies of bipolar disorder (Bauer et al. 2012). All patients received pharmaceutical treatment as usual throughout the study. All participants were volunteers and provided written informed consent. The study was approved by each local institutional review board.

\section{Data collection}

Patients self-reported all drugs taken daily, using ChronoRecord software in their native language installed on a home computer. The ChronoRecord software was previously validated and described in detail (Bauer et al. 2004, 2008). In addition to drugs taken, patients enter mood, sleep, and significant life events daily, and weight weekly. During patient training, each drug taken for bipolar disorder was selected from a list of psychotropic drugs in the software, displayed by brand and generic names for the country where the patient resides. For each selected drug, the pill strength was chosen from a list of available strengths. Every day, for each drug, the patient entered the total number of pills taken. Patients could enter partial pills $(1 / 4,1 / 2$, or $3 / 4)$ for tablets but not capsules. If a drug was not taken, the patient entered 0 pills for that drug. The patient could modify the drugs taken throughout the study period as needed, and a drug not included in the software list could be added by the patient.

\section{Medication classes}

Four medication classes were analyzed: mood stabilizers, antidepressants, antipsychotics, and benzodiazepines. Mood stabilizers were defined as lithium, valproate, lamotrigine, carbamazepine, or oxcarbazepine. Second-generation antipsychotics are also effective mood stabilizers, but were classified separately to better distinguish the medications taken and to enable comparison with prior research. Although controlled trials of an antimanic effect for benzodiazepines are lacking (Curtin and Schulz 2004), benzodiazepines were included since they are commonly prescribed to patients with bipolar disorder (Baldessarini et al. 2007; Simon et al. 2004).

\section{Polypharmacy}

Polypharmacy was defined as the use of two or more psychotropic drugs. Polypharmacy may involve two or more drugs from the same medication class such as two mood stabilizers or from different medication classes such as a mood stabilizer and an antidepressant.

\section{Drug analyses}

The daily self-reported data were used for all analyses. For each patient, for each day, taking a drug was defined as taking at least a fraction of a pill per day, regardless of dose. Taking a medication class was defined as taking any drug within the medication class per day. A patient was considered to have a stable drug combination when the same combination of one or more drugs was taken for $\geq 50 \%$ of days. The stable drug combinations were determined to focus the analysis on medications used long term. For all patients, the number of daily changes to the drug combinations was also calculated.

\section{Drug load}

The World Health Organization developed a methodology to calculate drug load that is based on a measure of equipotency known as the defined daily dose (DDD; WHO 2011). The DDD is the average maintenance dose per day for a drug used for its main indication in adults. The ratio of the prescribed daily dose (PDD) to the DDD converts the daily dose strength into multiples of the DDD. A ratio of 1 means the dose taken is equal to the DDD, a ratio greater than 1 means the dose taken is larger than the standard dose, and a dose less than 1 means the dose taken is smaller than the standard dose. The drug load is the sum of the PDD/DDD ratio for all drugs taken within one medication class. Researchers have used a PDD/DDD ratio of 1.5 as the cutoff for an excessive drug load for antipsychotics (Barbui et al. 2006; Procyshyn et al. 2010) and a cutoff of 2.0 for anticonvulsants (Lammers et al. 1995).

The drug load was determined for antidepressants, benzodiazepines, and antipsychotics, but not for anticonvulsants since the available DDD was for the primary indication of epilepsy. In this study, the actual dose taken by the patient was used as the PDD. Only patients who took any drug within a medication class for $\geq 50 \%$ of days were included in the calculation. The PDD/DDD ratio was calculated for each drug and summed for all drugs taken within a medication class. If a patient took 
multiple regimens with the same drug count within a medication class, the PDD/DDD ratio for each regimen was weighted by the percent of days taken.

\section{Statistics}

Patients were included in this analysis if they returned a minimum of 150 days of drug data, including entries of 0 pills taken. The demographic characteristics of the patients with and without a stable drug combination were compared using chi-square tests for frequency of categorical variables or independent sample $t$ tests for mean values of continuous variables. Unequal variance was assumed for all $t$ tests. The demographic characteristics of patients with a stable drug combination who took different medication classes were also compared. Means are presented \pm the standard deviation (SD). SPSS version 20.0 (IBM SPSS, Armonk, NY, USA) was used for all calculations.

\section{Results}

Data were collected from 513 patients with bipolar disorder, of which $450(87.7 \%)$ returned sufficient data to be included in the study. The 450 patients returned a total of 99,895 days of data (mean 222.0 days). Of the 450 patients, 315 (70\%) resided in the USA, 53 (11.8\%) resided in Germany, 45 (10\%) resided in Canada, and 37 (8.2\%) resided elsewhere. The patients had a diagnosis of bipolar I disorder (272, 60\%), bipolar II disorder (157, $35 \%)$, or bipolar NOS $(17,4 \%)$. With a mean age of $40 \pm$ 11.3 years, $313(70 \%)$ were female and $137(30 \%)$ were male. The patients reported $2.4 \pm 4.0$ lifetime hospitalizations for bipolar disorder and an age of onset of 22.0 \pm 10.3 years. For the 450 patients, Table 1 shows the number and percent of days taking any drug within a medication class. Of the 242 patients taking an antipsychotic, only $31(12.8 \%)$ of patients were taking a typical antipsychotic for a total of $2.5 \%$ of days. Within each medication class, most of the 450 patients took a small number of specific drugs. As shown in Table 2, only eight antidepressants, five antipsychotics, and three benzodiazepines were taken by at least $5 \%$ of the patients.

The drug load analysis revealed that the more drugs taken within a medication class, the larger the mean PDD/DDD ratio (Table 3). Of the 450 patients, 236 were taking an antidepressant for $\geq 50 \%$ of days; $36 \%$ of their drug regimens included two or more antidepressants and had a PDD/DDD ratio of $>1.5$. Of the 450 patients, 176 were taking an antipsychotic for $\geq 50 \%$ of days; $23 \%$ of their drug regimens included two or more antipsychotics and had a PDD/DDD ratio of $>1.5$.

Of the 450 patients, 353 (78.4\%) took a stable drug combination for $\geq 50 \%$ of the days. There were no significant differences between the demographic characteristics of the patients who did or did not take a stable combination. Considering the stable combinations, there were 52 unique combinations when categorized by medication class (Table 4) and 231 unique combinations when categorized by specific drugs (Table 5). The characteristics of the stable drug combinations are summarized in Table 6. Of the 353 patients with a stable combination, 293 (83\%) were taking a mood stabilizer and $82.4 \%$ took three or less drugs. The stable drug combinations involved more than one medication class in 248 (70.3\%) of the 353 patients. Of the 353 patients, those taking antidepressants were older (42.7 versus 37.2 years, $p<0.001$ ) and more likely female $(58.5 \%$ of females versus $43.8 \%$ of males, $p=0.010$ ) than those not taking antidepressants. Those taking benzodiazepines were more likely female (27.4\% of females versus $12.5 \%$ of males, $p=0.002$ ) than those not taking benzodiazepines.

Most of the 97 patients without a stable drug combination were taking drugs but with less consistency. Only 26 patients took no drugs for $\geq 50 \%$ days. Few of the 97 patients took any drug in a medication class for $\geq 90 \%$ of days. Of the 97 patients, $84(86.6 \%)$ were taking a mood stabilizer. Although 47 of the 84 (56\%) were taking a

Table 1 Number of patients taking medication classes by percent of days $(N=450)$

\begin{tabular}{|c|c|c|c|c|}
\hline & $\begin{array}{c}\text { Mood stabilizers } \\
\qquad(\%)\end{array}$ & $\begin{array}{c}\text { Antidepressants } \\
N(\%)\end{array}$ & $\begin{array}{c}\text { Benzodiazepines } \\
N(\%)\end{array}$ & $\begin{array}{c}\text { Antipsychotics } \\
N(\%)\end{array}$ \\
\hline Not taking & $63(14.0)$ & $150(33.3)$ & $269(59.8)$ & $208(46.2)$ \\
\hline Taking & $387(86.0)$ & $300(66.7)$ & $181(40.2)$ & $242(53.8)$ \\
\hline Total & $450(100.0)$ & $450(100.0)$ & $450(100.0)$ & $450(100.0)$ \\
\hline \multicolumn{5}{|c|}{ Percent of days taking } \\
\hline$>0$ to $<10$ & $8(2.1)$ & $22(7.3)$ & $38(21.0)$ & $26(10.7)$ \\
\hline$\geq 10$ to $<50$ & $20(5.2)$ & $42(14.0)$ & $32(17.7)$ & $40(16.5)$ \\
\hline$\geq 50$ to $<90$ & $41(10.6)$ & $36(12.0)$ & $34(18.8)$ & $36(14.9)$ \\
\hline$\geq 90$ & $318(82.2)$ & $200(66.7)$ & $77(42.5)$ & $140(57.9)$ \\
\hline Total taking & $387(100.0)$ & $300(100.0)$ & $181(100.0)$ & $242(100.0)$ \\
\hline
\end{tabular}

Includes any drug taken within the medication class. 
Table 2 Most common drugs taken by medication class $(N=450)$

\begin{tabular}{|c|c|}
\hline Medication & $N(\%)$ Patients \\
\hline \multicolumn{2}{|l|}{ Mood stabilizers } \\
\hline Lamotrigine & $204(45.3)$ \\
\hline Lithium & 151 (33.6) \\
\hline Valproate & $107(23.8)$ \\
\hline Oxcarbazepine & $51(11.3)$ \\
\hline Carbamazepine & $27(6.0)$ \\
\hline \multicolumn{2}{|l|}{ Antidepressants } \\
\hline Bupropion & $100(22.2)$ \\
\hline Venlafaxine & $53(11.8)$ \\
\hline Escitalopram & $44(9.8)$ \\
\hline Sertraline & $42(9.3)$ \\
\hline Trazodone & $41(9.1)$ \\
\hline Fluoxetine & $37(8.2)$ \\
\hline Citalopram & $37(8.2)$ \\
\hline Duloxetine & $29(5.4)$ \\
\hline \multicolumn{2}{|l|}{ Benzodiazepines } \\
\hline Clonazepam & 97 (21.6) \\
\hline Lorazepam & $62(13.8)$ \\
\hline Alprazolam & $38(8.4)$ \\
\hline \multicolumn{2}{|l|}{ Antipsychotics } \\
\hline Quetiapine & $110(24.4)$ \\
\hline Olanzapine & $60(13.3)$ \\
\hline Aripiprazole & $53(11.8)$ \\
\hline Risperidone & $43(9.6)$ \\
\hline Ziprasidone & $30(6.7)$ \\
\hline
\end{tabular}

Drugs taken by $5 \%$ or more of the patients.

mood stabilizer for $\geq 90 \%$ of days, they were not taking the same drug throughout the sample period. Of the 97 patients, $69(71.1 \%)$ were taking an antipsychotic. Of the $69,14(20.3 \%)$ were taking any antipsychotic for $\geq 90 \%$ of days, but this reflected the sum of days taking different antipsychotics. Patients without a stable drug combination also had twice as many daily changes in drugs taken than those with a stable combination (16 versus 8 changes per year, $p<0.001)$.

\section{Discussion}

Patients were more likely to take a mood stabilizer than any other drug. About $80 \%$ of the 450 patients were taking a stable drug combination for $50 \%$ or more days. Consistent with prior research (Baldessarini et al. 2008a, b; Goldberg et al. 2009), the majority of patients were taking polypharmacy including $75 \%$ of those with a stable combination. About half the patients with a stable combination were taking an antidepressant, despite the ongoing controversy. There was no predominant
Table 3 Mean PDD/DDD ratio by number of drugs and medication class

\begin{tabular}{ccc}
$\begin{array}{c}\text { Number of drugs } \\
\text { in class }\end{array}$ & $\begin{array}{c}\text { Number of } \\
\text { regimens }^{\text {a }}(\%)\end{array}$ & $\begin{array}{c}\text { Mean (SD) PDD/DDD } \\
\text { ratio }\end{array}$ \\
\hline Antidepressants $^{\mathrm{b}}$ & & \\
1 & $204(64)$ & $1.3(1.1)$ \\
2 & $97(30)$ & $2.5(1.6)$ \\
3 & $15(5)$ & $3.5(2.0)$ \\
4 & $3(1)$ & $5.1(1.5)$
\end{tabular}

Benzodiazepines $^{c}$

$\begin{array}{ccc}1 & 107(80) & 0.6(0.8) \\ 2 & 24(18) & 1.4(1.3) \\ 3 & 2(2) & 4.0(1.5)\end{array}$

Antipsychotics $^{\mathrm{d}}$

$\begin{array}{ccc}1 & 167(77) & 0.7(0.7) \\ 2 & 47(22) & 2.2(2.0) \\ 3 & 3(1) & 7.4(6.5)\end{array}$

${ }^{\mathrm{a} S o m e}$ patients took multiple regimens with different number of drugs within a medication class; ${ }^{\mathrm{b}} 236$ patients took antidepressants for $50 \%$ or more days; ${ }^{c} 111$ patients took benzodiazepines for $50 \%$ or more days; ${ }^{d} 176$ patients took antipsychotics for $50 \%$ or more days.

Table 4 Most frequent stable combinations by medication class $(N=353)$

\begin{tabular}{lc}
\hline Combinations by class & Patients \\
\hline 1 Mood stabilizer & $\mathbf{N}(\%)$ \\
1 Mood stabilizer +1 antidepressant & $62(18)$ \\
1 Mood stabilizer +1 antipsychotic & $45(13)$ \\
1 Mood stabilizer +1 antidepressant +1 antipsychotic & $31(9)$ \\
1 Antidepressant & $15(4)$ \\
2 Mood stabilizers & $15(4)$ \\
2 Mood stabilizers +1 antipsychotic & $15(4)$ \\
1 Mood stabilizer +1 antidepressant +1 benzodiazepine & $13(4)$ \\
2 Mood stabilizers +1 antidepressant & $12(3)$ \\
1 Antidepressant +1 antipsychotic & $10(3)$ \\
1 Mood stabilizer +2 antidepressants +1 antipsychotic & $10(3)$ \\
1 Mood stabilizer +2 antidepressants & $10(3)$ \\
1 Antipsychotic & $9(3)$ \\
1 Mood stabilizer +1 benzodiazepine & $8(2)$ \\
2 Mood stabilizers +1 benzodiazepine & $7(2)$ \\
2 Mood stabilizers +1 antidepressant +1 antipsychotic & $7(2)$ \\
1 Mood stabilizer +1 antidepressant +1 benzodiazepine +1 & $6(2)$ \\
2 Antipsychotic & $5(1)$ \\
\hline & $5(1)$ \\
\hline
\end{tabular}

Only combinations taken by five or more patients included. Data from 292 $(83 \%)$ of 353 patients and $19(37 \%)$ of 52 unique combinations by class. 
Table 5 Most frequent stable combinations by specific drug $(N=353)$

\begin{tabular}{lc}
\hline $\begin{array}{l}\text { Combinations } \\
\text { by drug }\end{array}$ & $\begin{array}{c}\text { Number of } \\
\text { patients }\end{array}$ \\
\hline Monotherapy & 21 \\
Lithium & 20 \\
Lamotrigine & 17 \\
Valproate & 4 \\
Bupropion & 4 \\
Quetiapine & 3 \\
Oxcarbazepine & 3 \\
Citalopram & 2 \\
Clonazepam & 2 \\
Paroxetine & 2 \\
Olanzapine & 2
\end{tabular}

Two drugs

\begin{tabular}{|c|}
\hline Lithium + lamotrigine \\
\hline Lamotrigine + quetiapine \\
\hline Lamotrigine + venlafaxine \\
\hline Valproate + bupropion \\
\hline Lamotrigine + clonazepam \\
\hline Lithium + quetiapine \\
\hline Valproate + lamotrigine \\
\hline Lamotrigine + bupropion \\
\hline Lamotrigine + citalopram \\
\hline Lamotrigine + risperidone \\
\hline Oxcarbazepine + fluoxetine \\
\hline Oxcarbazepine + quetiapine \\
\hline Bupropion + escitalopram \\
\hline Carbamazepine + citalopram \\
\hline Carbamazepine + lamotrigine \\
\hline Valproate + quetiapine \\
\hline Valproate + sertraline \\
\hline Lamotrigine + fluvoxamine \\
\hline Lamotrigine + escitalopram \\
\hline Lamotrigine + fluoxetine \\
\hline Lithium + venlafaxine \\
\hline Lithium + olanzapine \\
\hline Fluoxetine + olanzapine \\
\hline Oxcarbazepine + bupropion \\
\hline Venlafaxine + aripiprazole \\
\hline e drugs \\
\hline Lamotrigine + clonazepam + quetiapine \\
\hline Lamotrigine + venlafaxine + clonazepam \\
\hline Lithium + carbamazepine + olanzapine \\
\hline Lithium + lamotrigine + clonazepam \\
\hline
\end{tabular}

Table 5 Most frequent stable combinations by specific drug $(N=353)$ (Continued)

\begin{tabular}{ll}
\hline Lithium + lamotrigine + quetiapine & 2 \\
Lithium + lamotrigine + olanzapine & 2 \\
Four or more drugs \\
$\quad$ Lithium + lamotrigine + clonazepam + \\
$\begin{array}{l}\text { quetiapine } \\
\text { Lamotrigine + bupropion + paroxetine + } \\
\text { quetiapine + aripiprazole }\end{array}$ & 2 \\
\hline
\end{tabular}

Only combinations taken by more than one patient included. Data from 167 (47\%) of 353 patients and $43(19 \%)$ of 231 unique combinations by drug.

treatment regimen, as the stable combinations consisted of 52 unique combinations by medication class and 231 unique combinations by specific drugs.

This study cannot distinguish whether or not patients were taking polypharmacy because they were refractory to monotherapy. In a study of US medical claims, about one third of patients with bipolar disorder received initial treatment with polypharmacy (Baldessarini et al. 2008a). Also, polypharmacy is routinely prescribed to inpatients (Greil et al. 2012; Vincenti et al. 2010; Wolfsperger et al. 2007). Recent research suggests that monotherapy with a mood stabilizer or second-generation antipsychotic is generally effective for acute mania (Goldberg et al. 2009; Grunze et al. 2009; Malhi et al. 2012; Tamayo et al. 2010), but polypharmacy is often required for acute depression, mixed states, and maintenance (Goldberg et al. 2009; Malhi et al. 2012; Tamayo et al. 2010). However, polypharmacy increases the risk of drug interactions and adverse events (Besag and Berry 2006; Mojtabai and Olfson 2010; Sandson et al. 2005). In a US national study, psychotropics were a common cause of emergency department visits for adverse drug reactions for those under age 65 (Lucado et al. 2011). The challenge of polypharmacy is that the gain in stability from adding another drug must outweigh the safety risks and side effects (Malhi et al. 2012).

In the current study, the use of more than one drug within a medication class greatly increased the drug load. Patients taking two antipsychotics, antidepressants, or benzodiazepines had about double the drug load of those taking one drug, similar to prior findings (Procyshyn et al. 2010; Tognoni 1999). This result suggests that within a medication class, increasing the dose of one drug produces a lower drug load than adding a second drug. In patients with epilepsy, anticonvulsant polypharmacy is associated with a much higher drug load than with monotherapy, and a higher drug load is associated with increased adverse events (Lammers et al. 1995; Deckers et al. 2001; Deckers 2002). In contrast to that in epilepsy, polypharmacy in bipolar disorder primarily involves drugs from more than one medication class, as with $70 \%$ of the patients taking a stable combination in this study. There are few studies of the relation 
Table 6 Characteristics of the stable drug combinations $(N=353)$

\begin{tabular}{cc}
\hline & $\boldsymbol{N}(\%)$ \\
\hline Number of drugs & $87(24.6)$ \\
1 & $117(33.1)$ \\
3 & $87(24.6)$ \\
$\geq 4$ & $62(17.6)$ \\
Mean number (SD) & $2.4(1.2)$ \\
Number of medication classes & $105(29.7)$ \\
1 & $160(45.3)$ \\
2 & $72(20.4)$ \\
3 & $16(4.5)$ \\
4 & $2.0(0.8)$ \\
Mean number (SD) & \\
Taking medication class & $293(83.0)$ \\
Mood stabilizer & $190(53.8)$ \\
Antidepressant & $80(22.7)$ \\
Benzodiazepine & $142(40.2)$ \\
Antipsychotic &
\end{tabular}

between drug load as measured by the PDD/DDD ratio and adverse events for psychotropic drugs. For example, while persistent exposure to antipsychotic polypharmacy increases the risk of adverse reactions (Carnahan et al. 2006; Centorrino et al. 2004), the optimal measure to predict adverse events is unclear (Barr et al. 2010; Nosè et al. 2008). However, the drug load concept may be useful for improving tolerability of polypharmacy in bipolar disorder, and investigation of the relation between drug load and adverse reactions is indicated.

It is noteworthy that over $80 \%$ of the patients with a stable combination were taking three or less drugs. A relatively small number of drugs may facilitate long-term use, and there may be an upper limit on the number of daily drugs beyond which adherence decreases (Bauer et al. 2009; Robertson et al. 2008). Polypharmacy regimens that require frequent dosing, have dietary or time requirements, or are expensive may contribute to nonadherence (Cramer et al. 1989; Ingersoll and Cohen 2008). Patients with bipolar disorder consistently report that side effects contribute to nonadherence (Baldessarini et al. 2008b; Perlick et al. 2004). In this study, the patients without a stable combination were taking drugs, but inconsistently, with drug changes more than once a month. This finding is in agreement with prior evidence that nonadherence in bipolar disorder is typically partial or intermittent rather than complete (Baldessarini et al. 2008a; Lingam and Scott 2002).

There are many limitations to this analysis. All study patients had access to a psychiatrist and were taking medication. Furthermore, the very process of daily recording may improve medication adherence (van Berge Henegouwen et al. 1999). In clinical practice, most patients would not volunteer to keep a long-term daily record. This study may be less generalizable to other patients with bipolar disorder. With a naturalistic design, the patients in this study varied in severity, phase and course of the disease, and years of illness. The study included more females than males and more patients with bipolar I than bipolar II disorder. All data were selfreported and daily access to a computer was required. The strengths of this study include the use of prospective data from a relatively large number of patients and the entry of specific drugs and dose taken daily. However, the prescribed regimens and reasons for addition of new drugs were not known. Some drugs may be misclassified as to prescribing intent. For example, trazodone is considered an antidepressant but is frequently prescribed as a hypnotic agent. The analyses did not include other classes of psychotropic drugs such as stimulants, drugs taken for medical conditions, and over-the-counter preparations. Finally, many diverse factors that may influence medication selection such as physician prescribing habits, drug costs, regulatory influences, insurance plan formularies, pharmaceutical marketing, and patient preferences were not considered (Thistlewaite et al. 2010; Poulsen 1992).

\section{Conclusions}

Treatment of bipolar disorder is individualized in clinical practice as illustrated by 231 unique stable drug combinations for 353 patients. Other than the use of a mood stabilizer, no patterns were found within the stable combinations. A very large number of drug combinations may be prescribed. Considering only the most commonly taken drugs in this study (eight antidepressants, five antipsychotics, and four mood stabilizers), there are 32 possible combinations of mood stabilizer and antidepressant drugs, 20 possible combinations of mood stabilizer and antipsychotic drugs, and 160 possible combinations of mood stabilizer, antidepressant, and antipsychotic drugs. There will never be clinical trials of all possible combination therapies for bipolar disorder. Although controlled studies of polypharmacy are increasing, only limited evidence of effectiveness and safety is available to assist the clinician (Lin et al. 2006; Malhi et al. 2012; Beynon et al. 2009; Ghaemi and Ko, 2002). Further complicating drug selection, patients often have comorbid psychiatric and medical illnesses (Kupfer 2005; McIntyre et al. 2006), including those related to psychotropic drug use (McIntyre et al. 2006; Fagiolini et al. 2005). Some drug regimens in this study may appear inconsistent with current guidelines, but we assume that these are the best regimens for the 
circumstances of the individual patient. However, the wide variation in drug regimens and numerous possible drug combinations suggests that clinicians need more evidence to optimize treatment. While neuroscience research offers hope for a future with specifically targeted drugs (Insel 2009), the routine use of polypharmacy highlights the importance of clinical judgment in the current treatment of bipolar disorder.

\section{Competing interests}

MB was a consultant to AstraZeneca, Lilly, Servier, Lundbeck, Pfizer, BMS\&Otsuka, and GlaxoSmithKline. KS was a consultant to MERCK and Sunovion. ES was a consultant to EPAX, Lundbeck, AstraZeneca, and BMS. $M A, P G, T G, R M, W M, P R$, and PCW declare no competing interests.

\section{Authors' contributions}

$M A, M B, K S, W M, P G, P R, E S$ and $R M$ were involved with data collection. TG completed the data analysis. MB, PCW, and TG provided a first draft, commented by the other authors. All authors read and approved the final manuscript.

\section{Author details}

${ }^{1}$ Department of Psychiatry and Psychotherapy, Universitätsklinikum Carl Gustav Carus, Technische Universität Dresden, Fetscherstr. 74, Dresden 01307, Germany. ${ }^{2}$ ChronoRecord Association Inc., Fullerton, CA 92834, USA. ${ }^{3}$ Department of Psychiatry, Dalhousie University, Halifax, NS B3H 4R2, Canada. ${ }^{4}$ Department of Psychiatry, University of Missouri Kansas City School of Medicine, Kansas City, MO 64110, USA. ${ }^{5}$ Department of Psychiatry, University of Massachusetts, 55 Lake Avenue North, Worcester, MA 01655, USA. ${ }^{6}$ Department of Psychiatry, University of Toronto, Toronto, Ontario M5S 1A1, Canada. ${ }^{7}$ Mood Disorders Centre of Ottawa, Ottawa, Ontario K1G 4G3, Canada. ${ }^{8}$ Department of Psychiatry, University of California San Diego, San Diego, CA 92093, USA. ${ }^{9}$ Department of Psychiatry and Biobehavioral Sciences, Semel Institute for Neuroscience and Human Behavior University of California Los Angeles (UCLA), 300 UCLA Medical Plaza, Los Angeles, CA 90095, USA.

Received: 6 December 2012 Accepted: 25 January 2013 Published: 3 May 2013

\section{References}

Azorin JM, Aubrun E, Bertsch J, Reed C, Gerard S, Lukasiewicz M. Mixed states vs. pure mania in the French sample of the EMBLEM study: results at baseline and 24 months - European mania in bipolar longitudinal evaluation of medication. BMC Psychiatry. 2009; 9:33.

Baldessarini R, Henk H, Sklar A, Chang J, Leahy L. Psychotropic medications for patients with bipolar disorder in the United States: polytherapy and adherence. Psychiatr Serv. 2008a; 59:1175-83.

Baldessarini RJ, Perry R, Pike J. Factors associated with treatment nonadherence among US bipolar disorder patients. Hum Psychopharmacol. 2008b; 23:95-105.

Baldessarini RJ, Leahy L, Arcona S, Gause D, Zhang W, Hennen J. Patterns of psychotropic drug prescription for U.S. patients with diagnoses of bipolar disorders. Psychiatr Serv. 2007; 58:85-91.

Barbui C, Nosè M, Mazzi MA, Thornicroft G, Schene A, Becker T, Bindman J, Leese M, Helm H, Koeter M, Weinmann S, Tansella M. Persistence with polypharmacy and excessive dosing in patients with schizophrenia treated in four European countries. Int Clin Psychopharmacol. 2006; 21:355-62.

Barr AM, Honer WG, Johnson JL, WU TK, Procyshyn RM. A comparison of antipsychotic drug-defined daily doses versus chlorpromazine equivalent doses in patients with or without extrapyramidal motor symptoms. I Clin Psychopharmacol. 2010; 30:741-3.

Bauer M, Glenn T, Keil M, Bauer R, Marsh W, Grof P, Alda M, Sagduyu K, Murray G, Quiroz D, Baethge C, Whybrow PC. Brief depressive symptoms in patients with bipolar disorder: analysis of long-term self-reported data. Aust N Z J Psychiatry. 2012; 46:1068-78.

Bauer M, Glenn T, Grof P, Schmid R, Pfennig A, Whybrow PC. Subsyndromal mood symptoms: a useful concept for maintenance studies of bipolar disorder? Psychopathology. 2010; 43:1-7.
Bauer M, Glenn T, Grof P, Marsh W, Sagduyu K, Alda M, Murray G, Lewitzka U, Schmid R, Haack S, Whybrow PC. The association between concurrent psychotropic medications and self-reported adherence with taking a mood stabilizer in bipolar disorder. Hum Psychopharmacol. 2009; 25:47-54.

Bauer M, Wilson T, Neuhaus K, Sasse J, Pfennig A, Lewitzka U, Grof P, Glenn T, Rasgon N, Bschor T, Whybrow PC. Self-reporting software for bipolar disorder: validation of ChronoRecord by patients with mania. Psychiatry Res. 2008; 159:359-66.

Bauer M, Grof P, Gyulai L, Rasgon N, Glenn T, Whybrow PC. Using technology to improve longitudinal studies: self-reporting with ChronoRecord in bipolar disorder. Bipolar Disord. 2004; 6:67-74.

Beynon S, Soares-Weiser K, Woolacott N, Duffy S, Geddes JR. Pharmacological interventions for the prevention of relapse in bipolar disorder: a systematic review of controlled trials. J Psychopharmacol. 2009; 23:574-91.

Besag FM, Berry D. Interactions between antiepileptic and antipsychotic drugs. Drug Saf. 2006; 29:95-118.

Carnahan RM, Lund BC, Perry PJ, Chrischilles EA. Increased risk of extrapyramidal side-effect treatment associated with atypical antipsychotic polytherapy. Acta Psychiatr Scand. 2006; 113:135-41.

Centorrino F, Goren JL, Hennen J, Salvatore P, Kelleher JP, Baldessarini RJ. Multiple versus single antipsychotic agents for hospitalized psychiatric patients: case-control study of risks versus benefits. Am J Psychiatry. 2004; 161:700-6.

Cramer JA, Mattson RH, Prevey ML, Scheyer RD, Ouellette VL. How often is medication taken as prescribed? A novel assessment technique. JAMA. 1989; 261:3273-7.

Curtin F, Schulz P. Clonazepam and lorazepam in acute mania: a Bayesian meta-analysis. J Affect Disord. 2004; 78:201-8.

Deckers CL. Overtreatment in adults with epilepsy. Epilepsy Res. 2002; 52:43-52.

Deckers CL, Hekster YA, Keyser A, van Lier HJ, Meinardi H, Renier WO. Monotherapy versus polytherapy for epilepsy: a multicenter double-blind randomized study. Epilepsia. 2001; 42:1387-94.

Fagiolini A, Frank E, Scott JA, Turkin S, Kupfer DJ. Metabolic syndrome in bipolar disorder: findings from the Bipolar Disorder Center for Pennsylvanians. Bipolar Disord. 2005; 7:424-30.

Frye MA, Ketter TA, Leverich GS, Huggins T, Lantz C, Denicoff KD, Post RM. The increasing use of polypharmacotherapy for refractory mood disorders: 22 years of study. J Clin Psychiatry. 2000; 61:9-15.

Ghaemi SN, Ko JY. Polypharmacy in bipolar disorder. In: Ghaemi SN, editor. Polypharmacy in psychiatry. New York: Marcel Dekker; 2002: p. 35-79.

Goldberg JF, Brooks JO 3rd, Kurita K, Hoblyn JC, Ghaemi SN, Perlis RH, Miklowitz DJ, Ketter TA, Sachs GS, Thase ME. Depressive illness burden associated with complex polypharmacy in patients with bipolar disorder: findings from the STEP-BD. J Clin Psychiatry. 2009; 70:155-62.

Greil W, Häberle A, Haueis P, Grohmann R, Russmann S. Pharmacotherapeutic trends in 2231 psychiatric inpatients with bipolar depression from the International AMSP Project between 1994 and 2009. J Affect Disord. 2012; 136:534-42.

Grunze H, Vieta E, Goodwin GM, Bowden C, Licht RW, Moller HJ, Kasper S. The World Federation of Societies of Biological Psychiatry (WFSBP) guidelines for the biological treatment of bipolar disorders: update 2009 on the treatment of acute mania. World J Biol Psychiatry. 2009; 10:85-116.

Hayes J, Prah P, Nazareth I, King M, Walters K, Petersen I, Osborn D. Prescribing trends in bipolar disorder: cohort study in the United Kingdom THIN primary care database 1995-2009. PLoS One. 2011; 6:e28725.

Ingersoll KS, Cohen J. The impact of medication regimen factors on adherence to chronic treatment: a review of literature. J Behav Med. 2008; 31:213-24.

Insel TR. Disruptive insights in psychiatry: transforming a clinical discipline. J Clin Invest. 2009; 119:700-5.

Kupfer DJ. The increasing medical burden in bipolar disorder. JAMA. 2005; 293:2528-30.

Lammers MW, Hekster YA, Keyser A, Meinardi H, Renier WO, van Lier H. Monotherapy or polytherapy for epilepsy revisited: a quantitative assessment. Epilepsia. 1995; 36:440-6.

Lin D, Mok H, Yatham LN. Polytherapy in bipolar disorder. CNS Drugs. 2006; 20:29-42.

Lingam R, Scott J. Treatment non-adherence in affective disorders. Acta Psychiatr Scand. 2002; 105:164-72.

Lucado J, Paez K, Elixhauser A. Medication-related adverse outcomes in U.S. hospitals and emergency departments, 2008. In: HCUP Statistical Brief \#109. 
Agency for Healthcare Research and Quality. Rockville, MD; 2011. http://www. hcup-us.ahrq.gov/reports/statbriefs/sb109.pdf. Accessed 25 March 2012.

Malhi GS, Bargh DM, McIntyre R, Gitlin M, Frye MA, Bauer M, Berk M. Balanced efficacy, safety, and tolerability recommendations for the clinical management of bipolar disorder. Bipolar Disord. 2012; 14(Suppl 2):1-21.

McIntyre RS, Konarski JZ, Soczynska JK, Wilkins K, Panjwani G, Bouffard B, Bottas A, Kennedy SH. Medical comorbidity in bipolar disorder: implications for functional outcomes and health service utilization. Psychiatr Serv. 2006; 57:1140-4.

Michalak EE, Yatham LN, Lam RW. Quality of life in bipolar disorder: a review of the literature. Health Qual Life Outcomes. 2005; 15(3):72.

Mojtabai R, Olfson M. National trends in psychotropic medication polypharmacy in office-based psychiatry. Arch Gen Psychiatry. 2010; 67:26-36.

Nosè M, Tansella M, Thornicroft G, Schene A, Becker T, Veronese A, Leese M, Koeter M, Angermeyer M, Barbui C. Is the defined daily dose system a reliable tool for standardizing antipsychotic dosages? Int Clin Psychopharmacol. 2008; 23:287-90.

Perlick DA, Rosenheck RA, Kaczynski R, Kozma L. Medication non-adherence in bipolar disorder: a patient-centered review of research findings. Clin Approaches Bipolar Disord. 2004; 3:56-64.

Post RM, Altshuler LL, Frye MA, Suppes T, Keck PE Jr, McElroy SL, Leverich GS, Luckenbaugh DA, Rowe M, Pizzarello S, Kupka RW, Grunze H, Nolen WA. Complexity of pharmacologic treatment required for sustained improvement in outpatients with bipolar disorder. J Clin Psychiatry. 2010; 71:1176-86.

Poulsen RL. Some current factors influencing the prescribing and use of psychiatric drugs. Public Health Rep. 1992; 107:47-53.

Procyshyn RM, Honer WG, Wu TK, Ko RW, Mclsaac SA, Young AH, Johnson JL, Barr AM. Persistent antipsychotic polypharmacy and excessive dosing in the community psychiatric treatment setting: a review of medication profiles in 435 Canadian outpatients. J Clin Psychiatry. 2010; 71:566-73.

Quante A, Zeugmann S, Regen F, Engelhardt A, Anghelescu IG. Psychopharmacological treatment status in outpatients with bipolar disorder: a clinical survey in Germany. Psychiatry Investig. 2010; 7:155-62.

Robertson TA, Cooke CE, Wang J, Shaya FT, Lee HY. Effect of medication burden on persistent use of lipid-lowering drugs among patients with hypertension. Am J Manag Care. 2008; 14:710-6.

Sandson NB, Armstrong SC, Cozza KL. An overview of psychotropic drug-drug interactions. Psychosomatics. 2005; 46:464-94.

Simon NM, Otto MW, Weiss RD, Bauer MS, Miyahara S, Wisniewski SR, Thase ME, Kogan J, Frank E, Nierenberg AA, Calabrese JR, Sachs GS, Pollack MH, STEP-BD Investigators. Pharmacotherapy for bipolar disorder and comorbid conditions: baseline data from STEP-BD. J Clin Psychopharmacol. 2004; 24:512-20.

Smith LA, Cornelius V, Warnock A, Bell A, Young AH. Effectiveness of mood stabilizers and antipsychotics in the maintenance phase of bipolar disorder: a systematic review of randomized controlled trials. Bipolar Disord. 2007; 9:394-412.

Tamayo JM, Zarate CA Jr, Vieta E, Vázquez G, Tohen M. Level of response and safety of pharmacological monotherapy in the treatment of acute bipolar I disorder phases: a systematic review and meta-analysis. Int J Neuropsychopharmacol. 2010; 13:813-32.

Thistlewaite JE, Ajjawi R, Aslani P. The decision to prescribe: influences and choice. InnovAiT. 2010; 3:237-43.

Tognoni G. Pharmacoepidemiology of psychotropic drugs in patients with severe mental disorders in Italy. Italian Collaborative Study Group on the Outcome of Severe Mental Disorders. Eur J Clin Pharmacol. 1999; 55:685-90.

van Berge Henegouwen MT, van Driel HF, Kasteleijn-Nolst Trenite DG. A patient diary as a tool to improve medicine compliance. Pharm World Sci. 1999; 21:21-4.
Vincenti A, Ventriglio A, Baldessarini RJ, Talamo A, Fitzmaurice G, Centorrino F. Characteristics and clinical changes during hospitalization in bipolar and psychotic disorder patients with versus without substance-use disorders. Pharmacopsychiatry. 2010; 43:225-32

WHO. WHO Collaborating Centre for Drug Statistics Methodology. 2011. http:// www.whocc.no (2011). Accessed 26 March 2012.

Wolfsperger M, Greil W, Rössler W, Grohmann R. Pharmacological treatment of acute mania in psychiatric in-patients between 1994 and 2004. J Affect Disord. 2007; 99:9-17.

doi:10.1186/2194-7511-1-5

Cite this article as: Bauer et al:: Drug treatment patterns in bipolar disorder: analysis of long-term self-reported data. International Journal of Bipolar Disorders 2013 1:5.

\section{Submit your manuscript to a SpringerOpen ${ }^{\odot}$ journal and benefit from:}

- Convenient online submission

- Rigorous peer review

- Immediate publication on acceptance

- Open access: articles freely available online

- High visibility within the field

- Retaining the copyright to your article

Submit your next manuscript at $>$ springeropen.com 